\title{
Plasma growth hormone (GH), insulin and amino acid responses to arginine with or without aspartic acid in pigs. Effect of the dose
}

\author{
Alexis Cochard ${ }^{\mathrm{a} *}$, René Guilhermet ${ }^{\mathrm{a}}$, Michel Bonneau $^{\mathrm{b}}$ \\ ${ }^{a}$ Laboratoire du jeune ruminant, Inra-Ensar, 65, rue de Saint-Brieuc, \\ 35042 Rennes cedex, France \\ ${ }^{\mathrm{b}}$ Station de recherches porcines, Inra, 35590 Saint-Gilles, France
}

(Received 10 October 1997; accepted 20 March 1998)

\begin{abstract}
The aim of the present study was to examine, for the first time in pigs, the dosedependent effect of arginine (ARG) on growth hormone (GH) and insulin release and the effect of the combined ARG and aspartic acid (ASP) treatment on GH and insulin release. ARG ( 0.5 or $1 \mathrm{~g} / \mathrm{kg}$ body weight $)$ with or without an equimolar supplement of ASP $(0.38$ or $0.76 \mathrm{~g} / \mathrm{kg}$, respectively) was administered in piglets via the duodenum. ARG increased plasma arginine, ornithine, urea, proline and branched chain amino acid concentrations. ASP increased specifically plasma aspartic acid, glutamic acid, alanine and citrulline concentrations. Plasma insulin increased with no apparent difference between treatments. Maximum GH level and the area under the GH curve (AUC) were increased in a dose-dependent manner in response to ARG treatment. GH response to the combined ARG and ASP treatment (ARGASP) was delayed compared to ARG alone and was not dose-dependent. AUC for GH after ARGASP treatments were intermediate between those observed after the two ARG doses. Our data suggest that high ASP doses transiently inhibit and delay ARG-induced GH release in pigs and that an equimolar supplement of ASP stimulates or inhibits ARG-induced GH release depending on the dose used. (O) Inra/Elsevier, Paris
\end{abstract}

arginine / aspartic acid / growth hormone / insulin / plasma amino acids / pig

Résumé - Réponses plasmatiques de l'hormone de croissance (GH), de l'insuline et des acides aminés à l'arginine avec ou sans acide aspartique chez le porc. Effet de la dose. L'objectif de notre étude a été d'examiner, pour la première fois chez le porc, l'effet de la dose d'arginine (ARG) sur la sécrétion de l'hormone de croissance (GH) et de l'insuline et l'effet du traitement combiné d'ARG et d'ASP sur la sécrétion de la GH et de l'insuline. De l'ARG $(0.5$ ou $1 \mathrm{~g} / \mathrm{kg}$ de poids vif) avec ou sans un apport équimolaire d'ASP $(0.38$ ou $0.76 \mathrm{~g} / \mathrm{kg}$, respectivement) a été administrée chez des porcelets par voie intraduodénale. L'ARG a accru les concentrations plas-

\footnotetext{
* Correspondence and reprints

E-mail: cochard@roazhon.inra.fr
} 
matiques d'arginine, d'ornithine, d'urée, de proline et des acides aminés à chaîne ramifiée. L'ASP a accru spécifiquement les concentrations plasmatiques d'acide aspartique, d'acide glutamique, d'alanine et de citrulline. L'insuline plasmatique a été augmentée et aucune différence apparente n'a été observée entre les traitements. Les niveaux maximaux de GH et les aires sous la courbe de GH (AUC) ont été accrus de manière dose-dépendante en réponse aux traitements à l'ARG. La réponse de la GH au traitement combiné ARG-ASP (ARGASP) a été retardée par rapport aux traitements d'ARG seule et n'était pas dose-dépendante. Les AUC obtenues après les traitements ARGASP étaient intermédiaires entre celles observées pour les deux doses d'arginine. Nos données suggèrent que les doses élevées d'ASP inhibent et retardent la sécrétion de GH induite par l'ARG chez le porc et qu'un supplément équimolaire d'ASP stimule ou inhibe la sécrétion de GH induite par l'ARG selon la dose utilisée. (C) Inra/Elsevier, Paris

arginine / acide aspartique / hormone de croissance / insuline / acides aminés plasmatiques / porc

\section{INTRODUCTION}

Nutrients such as amino acids can alter metabolic hormone release [36]. Arginine (ARG) is a well-known stimulator of GH and insulin release.

ARG infused at the intravenous dose of $0.5 \mathrm{~g} / \mathrm{kg} / 30 \mathrm{~min}$ in humans elicits an increase in plasma $\mathrm{GH}[1,18-20,29,32]$ It is also used to detect $\mathrm{GH}$ release deficiencies. Abomasal, intraduodenal or intravenous infusions of ARG have been shown to stimulate $\mathrm{GH}$ secretion in rats [17], cattle [12,39], sheep [11, 13, 14, 23, $26]$ and pigs $[2,24]$. $\mathrm{GH}$ release in pigs is more refractory to ARG than in other species [24]. This is believed to be due to their somatostatinergic hypertone [35]. ARG-induced $\mathrm{GH}$ release is probably mediated by a decrease in the somatostatinergic tone as demonstrated indirectly by the use of cholinesterase inhibitors in man $[1,18,20]$ and pigs [10].

ARG also elicits insulin release in man $[4,33,38]$ and other mammals, including cattle [39], sheep [26] and pigs [2, 21]. ARG-induced insulin release is mediated by a depolarization of the plasma membrane of the pancreatic $\beta$-islet cells inducing the gating of the voltage-sensitive $\mathrm{Ca}^{2+}$ channels and the inflow of $\mathrm{Ca}^{2+}[5$, 22].
Few studies have reported the effects of aspartic acid (ASP) on GH and insulin release. In both sheep [26] and pigs [3], ASP elicits an increase in plasma GH which is even higher than that induced by ARG. In humans, ASP has no effect on $\mathrm{GH}$ release [8]. Depending on the dose used, a combined ARG and ASP treatment either decreased $(0.1 \mathrm{~g} / \mathrm{kg})$ or increased $(0.25 \mathrm{~g} / \mathrm{kg})$ plasma $\mathrm{GH}$ in the rat [16, 17]. In sheep, an intravenous dose of ASP $(0.4 \mathrm{~g} / \mathrm{kg} / 30 \mathrm{~min})$ has no effect on insulin release [26] while an intraduodenal dose ( $2 \mathrm{~g} / \mathrm{kg} /$ day) has been reported to stimulate insulin release [27].

ARG can be catabolized to ornithine (ORN) and urea by arginase whose highest activity is found in liver $[9,15,30]$. ORN can be catabolized in turn to glutamic acid (GLU), especially in the brain, via ornithine aminotransferase and pyrroline-5carboxylate dehydrogenase $[25,40]$. ORN has been shown to increase plasma $\mathrm{GH}$ in sheep [12] and is able to induce higher GH levels than ARG [13]. In both sheep [26] and pigs [3], GLU induces an increase in plasma $\mathrm{GH}$ which is even higher than that elicited by ARG.

A preliminary study conducted in our laboratories on pigs weighing $30-40 \mathrm{~kg}$ fed ad libitum revealed that some pigs were refractory to an intravenous dose of 
$0.5 \mathrm{~g} / \mathrm{kg} \mathrm{ARG}$, which is the dose commonly used in humans. It could be argued that the dose used was not high enough to elicit an efficient $\mathrm{GH}$ response owing to the supposed somatostatinergic hypertone of pigs. The present study was therefore undertaken to examine, for the first time in pigs, the dose-dependent effect of ARG on $\mathrm{GH}$ and insulin release and to determine whether ASP could increase ARGinduced plasma $\mathrm{GH}$ and insulin responses. Plasma amino acids and urea concentrations were measured in order to obtain information on the time-related pattern of the plasma levels of ARG, ASP and their related metabolites.

\section{MATERIALS AND METHODS}

\subsection{Animals and management}

Five female crossbred Yorkshire $\times$ Pietrain piglets from two litters were used in the experiment. They were 35 days of age and weighed $13.7 \pm 1.3$ (SE) kg at the beginning of the study. They were reared in compliance with national regulations for human care and the use of animals in research. They were housed in individual pens throughout the experiment. They were allowed water ad libitum and fed $70 \mathrm{~g} / \mathrm{kg}^{0.75}$ body weight of a standard diet provided in two meals per day. On the treatment days, the morning meal was delayed until the end of sampling. Animals were weighed the day before each treatment.

Eight days before the first injections, two catheters were inserted into each animal under general anesthesia $\left(\mathrm{O}_{2}\right.$ : halothane, $92: 8 \mathrm{v}: \mathrm{v}$, $2 \mathrm{~mL} / \mathrm{min}$ ): one into one of the external jugular veins and the other into the upper duodenum. Saline was flushed daily through the jugular catheter to keep it patent throughout the experiment.

\subsection{Treatments and blood sampling}

Five treatments were applied consecutively to each animal at 3-day intervals according to a $5 \times 5$ latin square design. The five treatments were as follows: i) deionized water (CONT), ii) $\mathrm{L}$-arginine at $0.5 \mathrm{~g} / \mathrm{kg}$ (ARG 1), iii) L-arginine at $1 \mathrm{~g} / \mathrm{kg}$ (ARG 2), iv) L-arginine at $0.5 \mathrm{~g} / \mathrm{kg}$ and L-aspartic acid at $0.38 \mathrm{~g} / \mathrm{kg}$ (ARGASP 1), and v) L-arginine at $1 \mathrm{~g} / \mathrm{kg}$ and $\mathrm{L}$-aspartic acid at $0.76 \mathrm{~g} / \mathrm{kg}$ (ARGASP 2). Equimolar amounts of $\mathrm{L}$-aspartic acid and $\mathrm{L}$-arginine were supplied (Degussa, Paris, France). The solutions (arginine at 5 or $10 \%$ in solution alone or in combination with aspartic acid at 3.8 or $7.6 \%$, respectively) were prepared in deionized water and injected manually with a syringe through the duodenal catheter from -5 to $-2 \mathrm{~min}$ at a flow rate of $60 \mathrm{~mL}$ per minute. Time 0 was 9.00. No side-effects were observed during and after the infusions.

Blood samples were collected in heparinized tubes through the jugular catheter at times $-30,-20,-10,0,10,20,30,40,50,60,70,80$, $90,100,110$ and $120 \mathrm{~min}$. Blood was cooled on ice and centrifuged immediately. Plasma for $\mathrm{GH}$ and insulin determination was stored at $-20^{\circ} \mathrm{C}$ until analysis.

\subsection{Measurement of plasma GH concentrations}

Plasma GH concentrations were determined by a specific homologous double-antibody radioimmunoassay as previously described [28] using a specific antibody raised in rabbits (UCB Bioproducts, Brussels, Belgium). USDA-GHI-1 (AFP-6 400) was used for iodination and standard curve. Sensitivity was $0.75 \mathrm{ng} / \mathrm{mL}$. Cross-reactivity with porcine prolactin, porcine luteinizing hormone, and porcine follicle-stimulating hormone was $<0.4 \%$. Intra-assay coefficients of variation were 9,13 and $15 \%$ for plasma samples containing 4.9, 15.2 and $32.9 \mathrm{ng} / \mathrm{mL}$, respectively. All samples were measured in duplicate within a single assay.

\subsection{Measurement of plasma insulin concentrations}

Plasma insulin concentrations were determined by a specific homologous double-antibody radioimmunoassay using a specific antibody raised in guinea-pigs (Miles Scientific, Naperville, IL, USA). Monomer porcine insulin (Novo Research Institute, Copenhague, Denmark) was used to generate a standard curve. Sensitivity was $1.5 \mu \mathrm{UI} / \mathrm{mL}$. ${ }^{125} \mathrm{I}$-insulin (Oris, Gif-sur-Yvette, France) was used for the competition. Intra-assay coefficients of 
variation were 12,9 and $11 \%$ for plasma samples containing $4.3,58.3$ and $252.1 \mu \mathrm{UI} / \mathrm{mL}$, respectively. All samples were measured in duplicate within a single assay.

\subsection{Measurement of plasma amino acid and urea concentrations}

Plasma free amino acids and urea concentrations were determined at 60 and $120 \mathrm{~min}$. Plasma samples were deproteinized with a $6 \%$ sulphosalicylic acid solution containing norleucine as an internal standard (v:v), centrifuged [31] and the supernatant was stored at $-20^{\circ} \mathrm{C}$ until analysis. Plasma amino acids and urea were separated by ion-exchange liquid chromatography using a Pharmacia LKB alphaplus serie II amino acid analyser equipped with a sulphonated polystyrene column and lithium citrate buffer. Amino acids and urea concentrations were determined by relating the chromatographic profile to that obtained with a standard after detection with ninhydrin. The concentrations were expressed in $\mu \mathrm{mol} / 100 \mathrm{~mL}$ plasma and the sensibility was $0.5 \mu \mathrm{mol} / 100 \mathrm{~mL}$. The tryptophane concentrations were under this limit of sensibility.

\subsection{Data analysis}

Areas under the curve (AUC) were estimated between 0 and $90 \mathrm{~min}$ for $\mathrm{GH}$ and between -10 and $60 \mathrm{~min}$ for insulin by calculating the areas between the $\mathrm{GH}$ or insulin curves and the basal levels extended to 90 or $60 \mathrm{~min}$, respectively. Basal level was obtained for $\mathrm{GH}$ by calculating the mean of the GH levels at $-30,-20$ and $-10 \mathrm{~min}$ and for insulin by calculating the mean of the insulin levels at -20 and $-10 \mathrm{~min}$.

Data were analysed by analysis of variance using the generalized linear model (GLM) procedure of the SAS system [37]. GH and insulin profiles were analysed using the repeated procedure of SAS including the main effects of animal and treatment. The main effect of time was analysed within treatments. Means GH and insulin levels were compared to basal levels and to CONT levels using the Dunnettu test. The model used for the analysis of AUC and amino acid concentrations included the main effects of animal and treatment. Multiple comparison of the means was carried out using the Duncan test.

\section{RESULTS}

\subsection{Plasma GH responses}

$\mathrm{GH}$ profiles from -30 to $90 \mathrm{~min}$ for CONT, ARG 1, ARG 2, ARGASP 1 and ARGASP 2 treatments, and the corresponding areas under the curve (AUC) are shown in figures 1 and 2, respectively.

The intraduodenal infusion of arginine at the doses of 0.5 and $1 \mathrm{~g} / \mathrm{kg}$ with or without equimolar amounts of aspartic acid induced an increase in plasma $\mathrm{GH}$ whose magnitude and time-related pattern differed significantly $(P<0.001)$ between treatments and animals.

\subsubsection{Plasma GH responses to ARG alone}

Plasma GH responded to arginine alone in a dose-dependent manner. ARG 1 induced a clear $\mathrm{GH}$ response. The maximum GH level for ARG 1 was 3 to 3.5 fold higher than the CONT value. The maximum GH level and AUC for ARG 2 were 2 fold higher than ARG 1. The maximum $\mathrm{GH}$ levels were observed at 30 and $20 \mathrm{~min}$ for ARG 1 and ARG 2, respectively.

Plasma GH for ARG 1 was significantly $(P<0.05)$ higher than CONT at 30 and $70 \mathrm{~min}$; however, it was not statistically different from basal level. Plasma GH for ARG 2 was significantly $(P<$ 0.05 ) higher than CONT between 0 and $40 \mathrm{~min}$ and at $70 \mathrm{~min}$ and higher than basal level at 20 and $30 \mathrm{~min}$. Plasma $\mathrm{GH}$ at 20 and $30 \mathrm{~min}$ and the AUC differed significantly $(P<0.05)$ between the two doses.

\subsubsection{Plasma GH responses to $A R G$ in association with equimolar supplement of ASP}

Plasma GH responded to ARG in association with ASP, although not in a dosedependent manner. The maximum GH levels for ARGASP treatments occurred 30 min later than the ARG treatments (at 

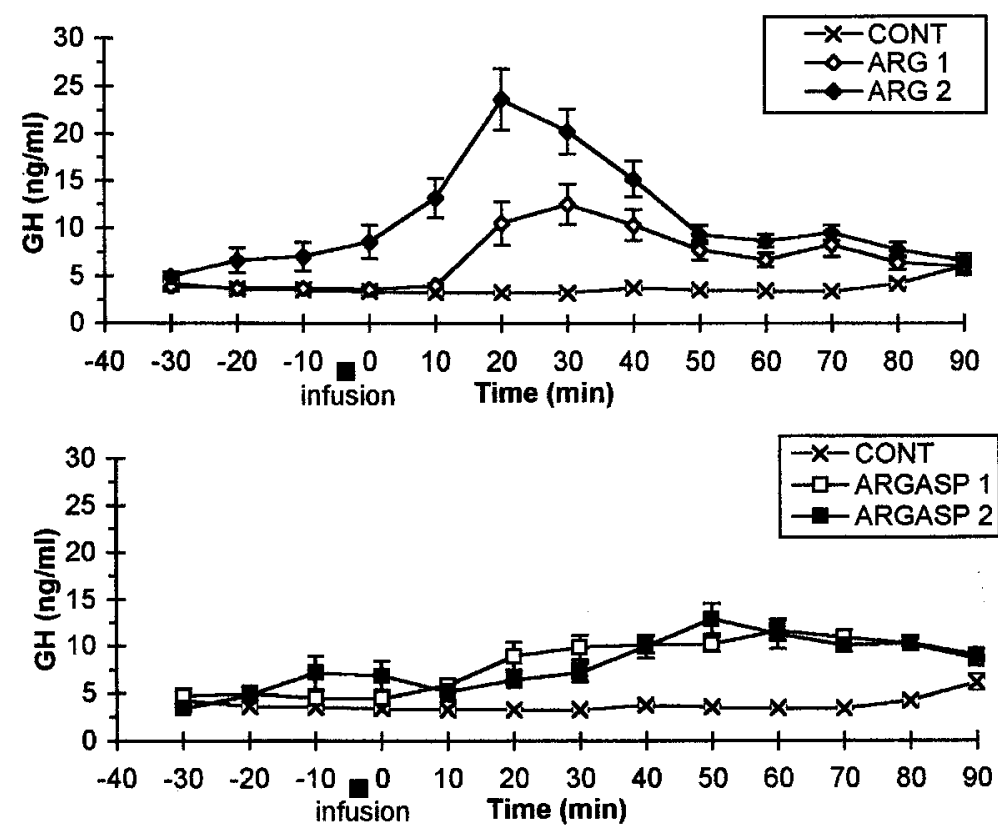

Figure 1. Plasma GH responses (means \pm SEM) to a) arginine alone (ARG 1, ARG 2) and to b) arginine in combination with aspartic acid (ARGASP 1, ARGASP 2). (CONT: control, ARG $1: 0.5 \mathrm{~g} / \mathrm{kg}$ arginine, ARG 2:1 g/kg arginine, ARGASP $1: 0.5 \mathrm{~g} / \mathrm{kg}$ arginine plus $0.38 \mathrm{~g} / \mathrm{kg}$ aspartic acid, ARGASP 2: $1 \mathrm{~g} / \mathrm{kg}$ arginine plus $0.76 \mathrm{~g} / \mathrm{kg}$ aspartic acid). Plasma $\mathrm{GH}$ concentrations were determined as mentioned in materials and methods $(n=5$ per treatment).

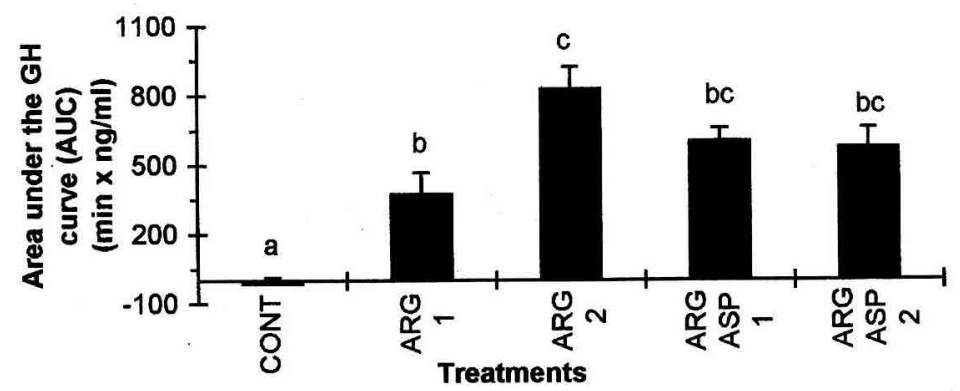

Figure 2. Plasma GH responses (area under the curve: AUC \pm SEM) to arginine alone (ARG 1 , ARG 2) or to arginine in combination with aspartic acid (ARGASP 1, ARGASP 2). AUC were determined between 0 and $90 \mathrm{~min}$ as mentioned in Materials and methods. Columns with different letters differ $(P<0.05)(n=5$ per treatment $)$.

60 and $50 \mathrm{~min}$, respectively, for ARGASP 1 and ARGASP 2) and were not different from that of ARG 1. The AUC for ARGASP treatments were intermediate between those of ARG treatments.
Plasma GH for ARGASP 1 was significantly $(P<0.05)$ higher than CONT values between 50 and $80 \mathrm{~min}$ and than basal level between 30 and $80 \mathrm{~min}$. Plasma GH for ARGASP 2 was significantly $(P<0.05)$ 
higher than CONT between 50 and $80 \mathrm{~min}$ and than basal value at 50 and $60 \mathrm{~min}$. Plasma GH and the AUC did not differ between the two doses of ARGASP.

Plasma GH did not differ between ARG 1 and ARGASP treatments except at $80 \mathrm{~min}(P<0.05)$. Plasma GH was significantly $(P<0.05)$ higher after ARG 2 than after ARGASP treatments between 10 and $40 \mathrm{~min}$. The AUC for ARGASP 1 tended to be higher than that of ARG 1 $(P<0.10)$ and the AUC for ARGASP 1 and ARGASP 2 tended to be lower than that of ARG $2(P<0.10)$.

\subsection{Plasma insulin responses}

Insulin profiles from -20 to $60 \mathrm{~min}$ for CONT, ARG 1, ARG 2, ARGASP 1 and ARGASP 2 treatments, and the corresponding AUC are shown in figures 3 and 4 , respectively.

The intraduodenal infusion of arginine at the doses of 0.5 and $1 \mathrm{~g} / \mathrm{kg}$ with or without equimolar amounts of aspartic acid induced a rapid increase in plasma insulin. The maximum insulin levels were measured after the end of infusions at time $0 \mathrm{~min}$. Insulin levels were 3 fold higher

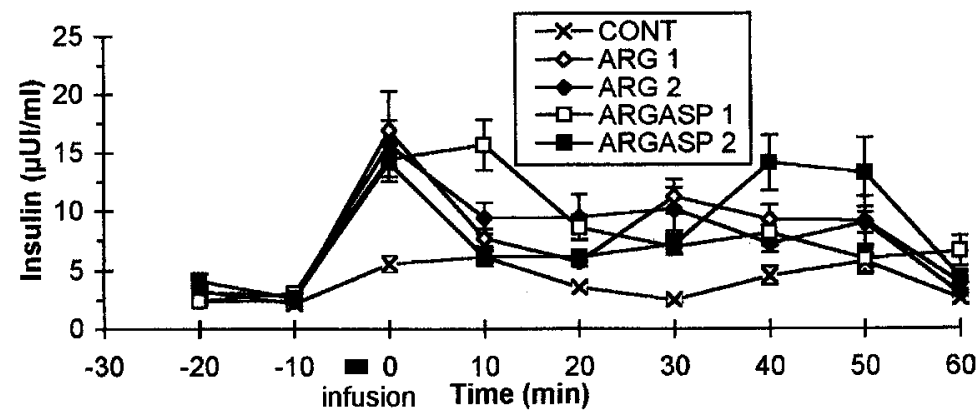

Figure 3. Plasma insulin responses (means \pm SEM) to arginine alone (ARG 1, ARG 2) or to arginine in combination with aspartic acid (ARGASP 1, ARGASP 2). Plasma insulin concentrations were determined as mentioned in Materials and methods ( $n=5$ per treatment).

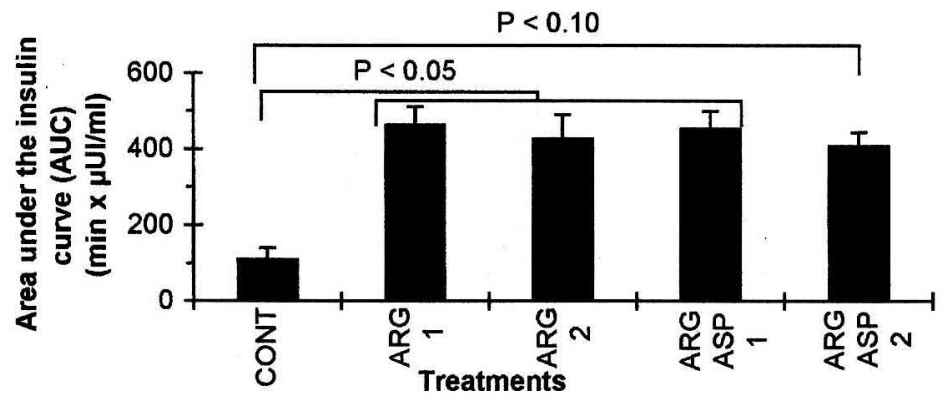

Figure 4. Plasma insulin responses ( $A U C \pm S E M$ ) to arginine alone (ARG 1, ARG 2) or to arginine in combination with aspartic acid (ARGASP 1, ARGASP 2). AUC were determined between -10 and 60 min as mentioned in Materials and methods ( $n=5$ per treatment). 
after ARG and ASPARG treatments than CONT at $0 \mathrm{~min}$. At $10 \mathrm{~min}$, insulin concentrations were half those observed at $0 \mathrm{~min}$ for all treatments except for ARGASP 1. The maximum insulin levels and AUC were not different between ARG and ARGASP treatments.

Plasma insulin was higher than CONT values at 0 and $30 \mathrm{~min}$ for ARG $1(P<0.05)$, at $0 \min (P<0.10)$ and at $30 \mathrm{~min}(P<0.05)$ for ARG 2, and at $10 \mathrm{~min}$ for ARGASP $1(P<0.05)$. Plasma insulin was significantly $(P<0.05)$ higher than basal level at 0 min for ARG 1, ARG 2 and ARGASP 1 and at $10 \mathrm{~min}$ for ARGASP 1 . AUC for CONT was significantly lower than those for ARG 1, ARG 2, ARGASP $1(P<0.05)$ and ARGASP $2(P<0.10)$.

\subsection{Plasma amino acids and urea responses}

Amino acids and urea concentrations measured at 60 and $120 \mathrm{~min}$ for CONT, ARG 1, ARG 2, ARGASP 1 and ARGASP 2 treatments are shown in table 1 .

The intraduodenal infusion of arginine at the doses of 0.5 and $1 \mathrm{~g} / \mathrm{kg}$ with or without equimolar amounts of aspartic acid changed the plasma levels of several amino acids and urea. The responses were dose-dependent and differed between ARG and ARGASP treatments. The magnitude of the response was higher at $60 \mathrm{~min}$ for ARGASP treatments and at 120 min for ARG treatments.

\subsubsection{Plasma responses for ARG, ornithine: $O R N$, urea, and citrulline: CIT}

ARG and ARGASP treatments increased significantly $(P<0.05)$ plasma ARG at 60 and $120 \mathrm{~min}$. Compared to the CONT value at $60 \mathrm{~min}$, plasma ARG was 7.8, 7.0, 10.4 and 9.1 fold higher for ARG 1, ARGASP 1, ARG 2 and ARGASP 2, respectively. Plasma ARG decreased between 60 and 120 min only for ARG 2
$(P<0.05)$ and ARGASP $2(P>0.10)$. No dose effect was observed except at $60 \mathrm{~min}$ for ARG treatments $(P<0.10)$.

ARG and ARGASP treatments increased significantly $(P<0.05)$ plasma ORN at 60 and $120 \mathrm{~min}$. Compared to the CONT value at $60 \mathrm{~min}$, plasma ORN was 5.1, 4.2, 7.0 and 4.7 fold higher for ARG 1, ARGASP 1, ARG 2 and ARGASP 2, respectively. Plasma ORN did not differ between 60 and $120 \mathrm{~min}$ for all treatments. A significant $(P<0.05)$ dose effect was observed at 60 and 120 min only for ARG treatments.

At $60 \mathrm{~min}$, plasma urea did not differ between the CONT and ARG 1 or ARGASP treatments. Plasma urea for ARG 2 was significantly $(P<0.05)$ higher compared to CONT. Plasma urea increased significantly $(P<0.05)$ between 60 and $120 \mathrm{~min}$ for the ARG and ARGASP treatments. Compared to the CONT value at $120 \mathrm{~min}$, plasma urea was 42, 66, 103 and $83 \%$ higher for ARG 1, ARGASP 1, ARG 2 and ARGASP 2 , respectively $(P<$ 0.05). A significant $(P<0.05)$ dose effect was observed for ARG treatments at 120 min.

CIT is an intermediate metabolite of urea cycle [30] and the precursor for the endogenous synthesis of arginine in the kidney [43]. Plasma CIT increased after ARGASP treatments. Plasma CIT was significantly higher than CONT values after ARGASP 1 at 60 and $120 \mathrm{~min}(P<0.05)$ and after ARGASP 2 at $60 \mathrm{~min}(P<0.10)$ and at $120 \min (P<0.05)$. No dose effect was observed.

\subsubsection{Plasma ASP responses}

Plasma ASP was significantly $(P<0.05)$ increased in a dose-dependent manner at 60 min after ARGASP treatment. Compared to the CONT value at $60 \mathrm{~min}$, plasma ASP was 38.5 and 69.0 fold higher for ARGASP 1 and ARGASP 2, respectively. Plasma ASP did not differ between 


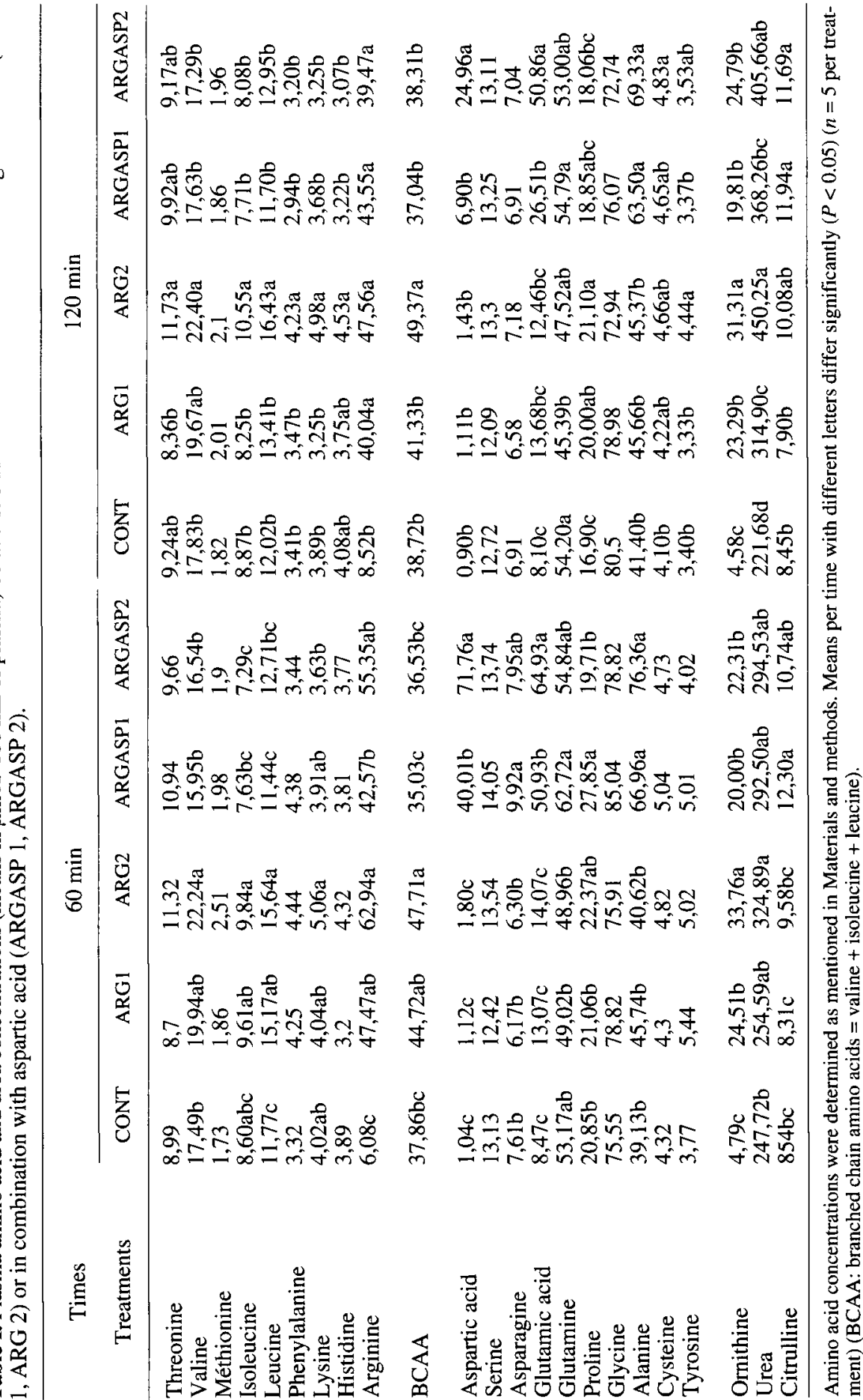


CONT and ARGASP 1 at 120 min while the ASP level was significantly $(P<0.05)$ increased after ARGASP 2 at $120 \mathrm{~min}$. Compared to the CONT value at $120 \mathrm{~min}$, plasma ASP was 7.7 and 27.7 fold higher for ARGASP 1 and ARGASP 2, respectively. Plasma ASP decreased significantly $(P<0.05)$ between 60 and $120 \mathrm{~min}$ for both ARGASP treatments.

\subsubsection{Plasma responses for the other amino acids}

The intraduodenal infusion of ARG alone at the doses of 0.5 and $1 \mathrm{~g} / \mathrm{kg}$ induced a $60 \%$ increase in plasma glutamic acid at 60 and $120 \mathrm{~min}(P>0.10)$, a $65 \%$ increase in plasma aspartic acid at both times $(P>0.10)$, a decrease in plasma glutamine at $120 \mathrm{~min}$ (ARG $1: P<0.10$; ARG 2: $P<0.05)$, an increase in plasma proline at $120 \mathrm{~min}(P<0.05)$. When ARG was administered alone at a dose of 1 $\mathrm{g} / \mathrm{kg}$, the branched chained amino acid (BCAA) concentrations, including leucine, valine and isoleucine, increased significantly $(P<0.05)$. Plasma levels for leucine $(P<0.05)$, valine $(P<0.10)$ and isoleucine $(P<0.05)$ differed significantly between the two doses at $120 \mathrm{~min}$. This effect was not reproduced when ARG and ASP were co-administered.

The intraduodenal infusion of the combination of ARG and ASP induced a significant $(P<0.05)$ increase in plasma glutamic acid (GLU) and alanine at 60 and $120 \mathrm{~min}$. Compared to the CONT, plasma GLU was 6.0 and 7.7 fold higher at 60 min and 3.3 and 6.3 fold higher at $120 \mathrm{~min}$ for ARGASP 1 and ARGASP 2, respectively. A significant $(P<0.05)$ dose effect on GLU levels was observed at $120 \mathrm{~min}$ but not at $60 \mathrm{~min}$. Plasma GLU decreased significantly $(P<0.05)$ between 60 and 120 min for both ARGASP treatments. No dose effect was observed at either time for plasma alanine. Plasma alanine did not differ between 60 and $120 \mathrm{~min}$.

\section{DISCUSSION}

Owing to a refractory growth hormone $(\mathrm{GH})$ release to arginine (ARG) in pigs ([24]; our preliminary observations), which is believed to be due to a somatostatinergic hypertone [35], the present study examined, for the first time in pigs, the dose-dependent effect of arginine (ARG) on GH and insulin release and the effect of the combined ARG and aspartic acid (ASP) treatment on GH and insulin release. Plasma amino acids and urea concentrations were measured in order to obtain information on the time-related pattern of the plasma levels of ARG, ASP and their related metabolites.

The fact that plasma ASP and plasma $\mathrm{ARG}$ were equivalent at $60 \mathrm{~min}$ and that the concentration of plasma ASP decreased more rapidly than that of ARG between 60 and 120 min showed that ASP was cleared from the plasma more rapidly than ARG. The maximal ARG level in the plasma was observed at $30 \mathrm{~min}$ after an intraduodenal administration of $1 \mathrm{~g} / \mathrm{kg}$ ARG (6.3, 76.2, 50.4, 44.6, 39.9 and 27.2 $\mu \mathrm{mol} / 100 \mathrm{~mL}$ at $-20,30,60,90,120,180$ min, respectively, unpublished results).

The increase in plasma urea and ornithine (ORN) after ARG treatment suggests that ARG was catabolized to urea and ornithine by arginase. Arginase activity is highest in liver [9, 15]. ARG can also be catabolized via arginase in the intestinal mucosa and the kidney $[6,15]$. The increase in plasma glutamic acid (GLU) and proline (PRO) after ARG treatment suggests that ORN was catabolized to pyrroline-5-carboxylate (P5C) via ornithine aminotransferase (OAT) and that P5C was catabolized to GLU via P5C dehydrogenase in liver and to PRO via $P 5 C$ reductase in the intestinal mucosa [25]. Plasma PRO has been previously reported to increase after ARG infusion in dairy cows [39]. The increase in plasma ASP after ARG treatment suggests that 
GLU neosynthesized from ORN was transaminated to ASP as previously shown [34]. The increase in branched chain amino acid (BCAA) concentrations, observed in the present study only after ARG treatments, has not been reported in previous studies which were, however, carried out on other species.

The increase in plasma GLU and ALA after ARGASP treatment suggested that ASP was transaminated to GLU as shown previously for the reverse reaction and that GLU was transaminated to ALA. Both these transaminations could prevent the neurotoxic effects of ASP and GLU which have been shown to occur at high doses [7]. The increase in plasma citrulline (CIT) concentration, observed in the present study only after ARGASP treatment, suggested that ASP supplied a precursor for CIT synthesis in the intestine mucosa which was probably GLU [44]. GLU is a potent nitrogen donor for the synthesis of carbamoyl-phosphate (CP) via $\mathrm{CP}$ synthase I (CPS-I) and CIT is synthesized from CP and ornithine via ORN transcarbamylase (OTC) [41, 42].

The maximal plasma insulin levels did not differ apparently between the two doses and between ARG and ARGASP treatments. In humans, a dose-dependent effect of ARG on insulin secretion has been reported $[4,38]$. Insulin secretion has previously been reported to be sensitive to ARG infused intravenously in pigs $[2,21]$. No change in plasma glucose was observed between -30 and $120 \mathrm{~min}$ in the present study (results not shown). The effect of ASP alone on insulin secretion was not examined in the present study. In sheep, ASP failed to change insulin levels [26]. The rapid insulin response in our study is consistent with an effect of the intraduodenal dose of ARG on pancreatic $\beta$-cells, as previously described [5, 22].

ARG alone increased plasma GH in a dose-dependent manner in the present study. It is the first time that the dose- dependent effect of ARG on GH release is reported in pigs. In short children, no difference in $\mathrm{GH}$ response has been reported between the doses of 0.2 and $0.5 \mathrm{~g} / \mathrm{kg}$ [4]. These data are consistent with the existence of a somatostatinergic hypertone in pigs $[24,35]$. Because the time-related pattern of GH secretion differed between animals, a more consistent response might have been obtained either with a higher dose of ARG or with an intravenous infusion of ARG.

The present study showed that ARGASP treatment induced a more delayed plasma $\mathrm{GH}$ response than ARG treatment and that the plasma $\mathrm{GH}$ response was not dose dependent. The maximum plasma GH levels after ARGASP treatments were observed 30 min later than after ARG treatments and were not different from that of ARG 1. The AUC for the ARGASP treatments were intermediate between those of the ARG treatments. It is the first time that the effect of the combined ARG and ASP treatment on $\mathrm{GH}$ release is reported in pigs. We expected, however, an increase in ARG-induced plasma GH response because ASP has been shown to elicit, in sheep and pigs, an increase in plasma GH [3, 26] which is even higher than that induced by ARG. Although the concentrations of ARG, its metabolites and ASP were not determined in the brain in the present study, the more rapid decrease in the plasma concentration of ASP than ARG suggested that ASP transiently inhibited and delayed ARG-induced GH release. When the inhibitory effect of ASP was no longer present, the remaining ARG or ORN probably induced a plasma $\mathrm{GH}$ response. An equimolar supplement of ASP stimulated ARG-induced GH release at the lower dose and inhibited ARG-induced GH release at the upper dose. It has been previously reported in rats that ARGASP has different effects on GH release depending on the dose used $[16,17]$. The discrepancy between the reported stimulating effect of 
ASP given alone on GH release in both pigs and sheep $[3,26]$ and the inhibitory effect suggested by the present results could be explained by the doses and the species used. ASP was previously infused at intravenous doses of $0.3 / \mathrm{kg}$ in sheep [26] and $0.15 \mathrm{~g} / \mathrm{kg}$ in pigs [3].

In conclusion, the present study suggests that a dose of $1 \mathrm{~g} / \mathrm{kg}$ ARG is more appropriate than the dose commonly used in humans $(0.5 \mathrm{~g} / \mathrm{kg})$ to study ARG effects on $\mathrm{GH}$ release in pigs owing to their supposed somatostatinergic hypertone. Our data suggest that high ASP doses transiently inhibit and delay ARG-induced $\mathrm{GH}$ release in pigs and that an equimolar supplement of ASP stimulates or inhibits ARG-induced $\mathrm{GH}$ release depending on the dose used. Further studies are needed at the supra hypothalamic level in order to determine the mechanisms by which ARG stimulates $\mathrm{GH}$ release and the mechanisms by which ASP affects ARGinduced $\mathrm{GH}$ release.

\section{ACKNOWLEDGMENTS}

The authors thank M. Formal for the measurement of plasma amino acid and urea concentrations and $\mathrm{Y}$. Lebreton, F. Giovanni and $\mathrm{M}$. Lesage for their contribution to the experiment. The GH preparation was a gift from the National Hormone and Pituitary Program (University of Maryland School of Medecine) and the National Institute of Diabetes and Kidney diseases.

\section{REFERENCES}

[1] Alba-Roth J., Muller A., Schopohl J., von Werder K., Arginine stimulates Growth Hormone secretion by suppressing endogenous somatostatin secretion, J. Clin. Endocrinol. Metab. 67 (1988) 1186-1189.

[2] Atinmo T., Baldijao C., Houpt K.A., Pond W.D., Barnes R.H., Plasma levels of growth hormone and insulin in protein malnourished vs normal growing pigs in response to arginine or glucose infusion, J. Anim. Sci 46 (1978) 409-416.
[3] Barb C.R., Campbell R.M., Armstrong J.D., Cox N.M., Aspartate and glutamate modulation of growth hormone secretion in the pig: Possible site of action, Domest. Anim. Endocrinol. 13 (1996) 81-90.

[4] Bellone J., Valetto M.R., Aimaretti G., Segni M., Volta C., Cardinale G., Baffoni C., Pasquino A.M., Bernasconi S., Bartolotta E., Effects of phenylalanine, histidine, and leucine on basal and GHRH-stimulated GH secretion and on PRL, insulin, and glucose levels in short children, comparison with the effects of arginine, J. Pediatr. Endocrinol. Metab. 9 (1996) 523-531.

[5] Blachier F., Mourtada A., Sener A., Malaisse W.J., Stimulus-secretion coupling of arginine-induced insulin release. Uptake of metab.olized and nonmetab.olized cationic amino acids by pancreatic islets, Endocrinology 124 (1989) 134-141.

[6] Blachier F., Darcy-Vrillon B., Sener A., Duée P.H., Malaisse W.J., Arginine metabolism in rat enterocytes, Biochim. Biophys. Acta 1092 (1991) 304-310.

[7] Boudouresque F., Chautard T., Jezova D., Becquet D., Guillaume V., Héry F., Giraud P., Grino M., Oliver C., Excitatory amino acids and adenopituitary hormone secretion in mammals, with special reference to development, Endocr. Reg. 25 (1991) 44-52.

[8] Carlson H.E., Miglieta J.T., Roginsky M.S., Stegink L.D., Stimulation of pituitary hormone secretion by neurotransmitter aminoacids in humans, Metabolism 38 (1989) 1179-1182.

[9] Civen M., Brown C.B., Trimmer B.M., Regulation of arginine responses of lambs fed rumen- protected ornithine and arginine, Small Ruminant Res. 17 (1967) 229-236.

[10] Cochard A., Guilhermet R., Bonneau M., Effect of arginine, growth hormone-releasing hormone (GHRH) and neostigmine administered singly or in paired combinations on growth hormone $(\mathrm{GH})$ release in pigs, Reprod. Nutr. Dev. 37 (1997) 589-598.

[11] Davenport G.M., Boling J.A., Schillo K.K., Nitrogen metabolism and somatotropin secretion in beef heifers receiving abomasal arginine infusions, J. Anim. Sci 68 (1990) 1683-1692.

[12] Davenport G.M., Boling J.A., Schillo K.K., Aaron D.K., Nitrogen metabolism and somatotropin secretion in lambs receiving arginine and omithine via abomasal infusion, J. Anim. Sci. 68 (1990) 222-232.

[13] Davenport G.M., Boling J.A., Schillo K.K., Growth and endocrine responses of lambs fed rumen-protected ornithine and arginine, Small Ruminant Res. 17 (1995) 229-236. 
[14] Davis S..L, Borger M.L., Hypothalamic catecholamine effects on plasma levels of prolactin and growth hormone in sheep, Endocrinology 92 (1973) 303-309.

[15] Edmonds M.S., Lowry K.R., Baker D.H., Urea cycle metabolism: effects of supplemental omithine or citrulline on performance, tissue amino acid concentrations and enzymatic activity in young pigs fed arginine-deficient diets, J. Anim. Sci. 65 (1987) 706-716.

[16] Franchimont P., Luyckx A., Campistron G., Cros J., Effets de l'aspartate d'arginine sur le sécrétion de somatotrophine, insuline et glucagon chez le rat, 'Thérapie 34 (1979) 641-647.

[17] Franchimont P., Campistron G., Creuzet M.H., Gros J., Luyckx A., Effects of arginine aspartate and its components on Growth Hormone, insulin and glucagon secretion in the rat, Arch. Int. Pharmacodyn 267 (1984) 161-168.

[18] Ghigo E., Bellone J., Mazza E., Imperiale E., Procopio M., Valente F., Lala R., de Sanctis C., Camanni F., Arginine potentiates the GHRH- but not the pyridostigmine-induced $\mathrm{GH}$ secretion in normal short children. Further evidence for a somatostatin supressing effect of arginine, Clin. Endocrinol. 32 (1990) 763-767.

[19] Ghigo E., Goffi F., Nicolosi M., Arvat E., Valente F., Mazza E., Ghigo M.C., Camanni F., Growth Hormone $(\mathrm{GH})$ responsiveness to combined administration of arginine and GHReleasing Hormone does not vary with age in man, J. Clin. Endocrinol. Metab. 71 (1990) 1481-1485.

[20] Ghigo E., Arvat E., Valente F., Nicolosi M., Boffano G.M., Procopio M., Bellone J., Mazza E., Camanni F., Arginine reinstates the somatotrope responsiveness to intermittent Growth Hormone-Releasing Hormone administration in normal adults, Neuroendocrinology 54 (1991) 291-294.

[21] Gustavsson S., Johansson H., Lundqvist G., Pancreatic hormonal release after glucose and arginine administration in anesthetized pigs, Acta Endocrinol. 93 (1980) 470-474.

[22] Herchuelz A., Lebrun P., Boschero A.C., Malaisse W.J., Mechanism of arginine-stimulated $\mathrm{Ca}^{2+}$ influx into pancreatic B cell, Am. J. Physiol. 246 (1984) E38-E43.

[23] Hertelendy F., Machlin L., Kipnis D.M., Further studies on the regulation of insulin and growth hormone secretion in sheep, Endocrinology 84 (1969) 192-199.

[24] Hertelendy F., Takahashi K., Machlin L.J., Kipnis D.M., Growth hormone and insulin secretory responses to arginine in the sheep, pig and cow, Gen. Comp. Endocrinol. 14 (1970) 72-77.
[25] Jones M.E., Conversion of glutamate to ornithine and proline: pyrroline-5-carboxylate, a possible modulator of arginine requirements, J. Nutr. 115 (1985) 509-515.

[26] Kuhara T., Ikeda S., Ohneda A., Sasaki Y., Effects of intravenous infusion of 17 amino acids on the secretion of $\mathrm{GH}$, glucagon, and insulin in the sheep, Am. J. Physiol. 260 (1991) E21--E26.

[27] Kuhara T., Katoh K., Oda S., Ohneda A., Sasaki Y., Responses of metabolic hormones to prolonged intraduodenal infusion of amino acids in sheep, Anim. Sci. Technol. 63 (1992) 1123-1133.

[28] Louveau I., Bonneau M., Salter D.N., Agerelated changes in plasma porcine growth hormone $(\mathrm{GH})$ profiles and insulin-like growth factor-I (IGF-I) concentrations in Large-White and Meishan pigs, Reprod. Nutr. Dev. 31 (1991) 205-216.

[29] Maccario M., Procopio M., Loche S., Cappa M., Martina V., Camanni F., Ghigo E., Interaction of free fatty acids and arginine on Growth Hormone secretion in man, Metabolism 43 (1994) 223-226.

[30] Meijer A.J., Lamers W.H., Chamuleau R.A., Nitrogen metabolism and ornithine cycle function, Physiol. Rev. 70 (1990) 701-748.

[31] Mondino A., Bongiovanni G., Fumero S., Rossi L., An improved method of plasma deproteinaton with sulphosalicylic acid for determination amino acids and related compounds, J. Chromatogr. 74 (1972) 255-263.

[32] Page M.D., Dieguez C., Valcani R., Edwards C., Hall R., Scanlon M.F., Growth Hormone (GH) response to arginine and L-dopa alone or after GHRH pretreatment, Clin. Endocrinol. 28 (1988) 551-558.

[33] Palmer J.P., Walter R.M., Ensinck J.W., Arginine stimulated acute phase of insulin and glucagon secretion, I. In normal man, Diabetes 24 (1975) 735-740.

[34] Parsons D.S., Volman-Mitchell H., The transamination of glutamate and aspartate during absorption in vitro by small intestine of chicken, guinea pig and rat, J. Physiol. 239 (1974) 677-694.

[35] Peticlerc D., Pelletier G., Lapierre H., Gaudreau P., Couture Y., Dubreuil P., Morisset J., Brazeau P., Dose response of two synthetic human growth hormone-releasing factors on growth hormone release in heifers and pigs, $\mathbf{J}$. Anim. Sci 65 (1987) 996-1005.

[36] Riis P.M., Adaptation of metabolism to various conditions, in: Neimann-Sørensen A., Tribe D.E. (Eds.), World Animal Science A3- Dynamic Biochemistry of Animal Production, Elsevier, Amsterdam, the Netherlands, 1983, pp. 319-358. 
[37] SAS, SAS User's Guide, SAS Institute, Cary, NC, USA, 1989.

[38] van Haeften T.W., Voetberg G.A., Gerich J.E., van der Veen E.A., Dose-response characteristics for arginine-stimulated insulin secretion in man and influence of hyperglycemia, J. Clin. Endocrinol. Metab. 69 (1989) 1059-1064.

[39] Vicini J.L., Clark J.H., Hurley W.L., Bahr J.M., Effects of abomasal or intraveinous administration of arginine on milk production, milk composition, and concentrations of somatotropin and insulin in plasma of dairy cows, J. Dairy Sci. 71 (1988) 658-665.

[40] Wroblewsky J.T., Blaker W.D., Meek J.L., Ornithine as a precursor of neurotransmitter glutamate: effects of canaline on ornithine aminotransferase activity and glutamate content in the septum of rat, Brain Res. 329 (1985) 161-172.

[41] Windmueller H.G., Spaeth A.E., Uptake and metabolism of plasma glutamine by the small intestine, J. Biol. Chem. 249 (1974) 5070-5079.

[42] Windmueller H.G., Spaeth A.E., Intestinal metabolism of glutamine and glutamate from the lumen as compared to glutamine from food, Arch. Biochem. Biophys. 171 (1975) $662-672$.

[43] Windmueller H.G., Spaeth A.E., (1981) Source and fate of circulating citrulline, Am. J. Physiol. 241, E473-E480. 